\title{
Humanoid robots go to school
}

\section{Christina Chalmers $^{1}\left(\mathbb{D} \cdot\right.$ Therese Keane $^{2}$ D $\cdot$ Marie Boden $^{3}$ (D) $\cdot$ Monica Williams $^{4}$}

Received: 27 October 2021 / Accepted: 20 January 2022 / Published online: 16 February 2022

(c) The Author(s) 2022

\begin{abstract}
Humanoid robots are being used in some schools, however, research on the use of these robots is relatively new. In this three-year study, humanoid robots were deployed in 10 schools, involving 29 teachers across early childhood to Year 10. This study aimed to ascertain teachers' perceptions of the benefits and challenges, the pedagogical practices that helped with student engagement, and where the robots fitted in the curriculum. Through multiple case studies, teachers' views were explored and results from the study supports the deployment of humanoid robots. The study advocates a constructivist inquiry approach to using humanoid robots across the curriculum.
\end{abstract}

Keywords Robotics $\cdot$ Humanoid robots $\cdot$ Programming

\section{Introduction}

The use of robots in education has been the subject of research over the past 25 years and many methodologies, courses, initiatives, and competitions have been developed in the context of educational robotics. Robots have been used to learn

Christina Chalmers

c.chalmers@qut.edu.au

Therese Keane

tkeane@swin.edu.au

Marie Boden

marieb@itee.uq.edu.au

Monica Williams

williamsm@ais.sa.edu.au

1 Faculty of Creative Industry, Education, and Social Justice, Queensland University of Technology, Brisbane, Queensland, Australia

2 Department of Education, Swinburne University of Technology, Melbourne, Australia

3 School of IT and Electrical Engineering, University of Queensland, Brisbane, Queensland, Australia

4 Association of Independent Schools of South Australia, Unley, South Australia, Australia 
about science, technology, engineering, and mathematics (STEM) concepts (Cejka et al., 2006). They have been used as a platform to learn about computers and computer programming (Bers et al., 2014); non-traditional robotics activities have also been introduced to help tell stories, to create puppets, and in music and art activities (Benitti, 2012). Numerous research studies suggest that robotics activities have a positive effect on the development of problem solving and the potential to improve and enhance the teaching and learning process (Barak \& Zadek, 2009; Barker and Ansorge, 2007; Bers and Portsmore, 2005; Castledine \& Chalmers, 2011; Welch \& Huffman, 2011). According to Bers (2008), even young children using and creating with age-appropriate robots are capable of developing unique ways of solving open-ended problems.

Previous studies on the use of robots in classrooms, however, have mainly focused on students; only a small number of research articles have concentrated on teachers' perceptions of the benefits and challenges of using robots in the classroom (Chalmers, 2018; Yadav et al., 2017). There is limited research on understanding teachers' perspetives on why humanoid robots are being used in the classroom and how they are used (Ceha et al., 2021). Understanding teachers' perceptions is important, as the adoption of new technologies in schools, including humanoid robots, depends on teachers' perceptions of the benefits of the technology for students' learning (Fridin \& Belokopytov, 2014). Teachers' attitudes towards technologies are reflected in their actions and pedagogical practices when engaging students with new technologies in their classrooms (Eickelmann \& Vennemann, 2017).

The purpose of this three-year qualitative research study was to explore teachers' views on the use of humanoid robots in the classroom and the pedagogical approaches adopted. This study focused on teachers' perceptions of the benefits and challenges of using humanoid robots in the classroom and how the robots fitted into the curriculum. In particular, the specific research questions that this study sought to answer were:

1. What are teachers' perceived value of the use of humanoid robots in the classroom?

2. What pedagogical practices are most effective when humanoid robots are used?

3. Which subject areas of the curriculum does the use of the humanoid robot engage students to learn?

While numerous research studies suggest that robotics activities have a positive effect on the learning process, the pedagogical approaches and teaching strategies are still being trialed with humanoid robots as they are relatively new to schools (Keane et al., 2016a). Working with humanoid robots, however, encourages a constructivist learning environment where student-guided inquiry is often applied (Keane et al., 2016a; Pedaste \& Altin, 2020). Technology-based activities, such as robotics, can help teachers explore new concepts and ways of thinking with their students (Chambers \& Carbonaro, 2003). This type of learning environment, according to Alimisis (2012), can engage "students' curiosity and initiate motivation" (p.2).

Within a technology-enhanced constructionist learning environment students are allowed to discover and make choices with technology as they collaboratively 
solve design challenges (Chambers \& Carbonaro, 2003). One of the early pioneers of technology activities in educational settings was Papert (1993) who believed learners build knowledge structures through the internalization of actions, by using digital technology tools to work through rich problems (Bers et al., 2014). Jonassen (2000) argued that technologies should be considered as cognitive tools or 'Mindtools', which could enhance problem-solving and enrich the learning process. A constructionist-learning environment incorporating technologies such as robotics, together with inquiry learning approach, has been shown to increase students' motivation for learning (Pedaste \& Altin, 2020).

Robotics-based activities can provide teachers with engaging contexts to apply deep-level and robust understandings of constructivism, constructionism, and inquiry-based learning; three of the major theoretical underpinnings of many 21st century learning models for enhancing teaching and learning (Alimisis, 2013; Eguchi, 2013; Keane et al., 2016a). These models emphasize collaboration, creative problem thinking and problem solving, and active learning.

\section{Methods}

A multiple case study design was chosen for this study to enable an exploration of the deployment of the humanoid robot in each school setting, as well as enabling a comparison between settings. Multiple case study design is sufficiently open-ended to enable researchers to develop an in-depth understanding and to reflect on the complexity of all cases (Creswell, 2008). This approach was chosen as it was important to understand what was being done in each setting, the depth of the learning, and the context. Examining contexts is integral to providing in-valuable explanations of the cases (Creswell, 2008; Stake, 2006). This perspective emphasizes the experience of the participants with a focus on qualitative analysis and enabled, in this study, an exploration of the use of the robots in each school setting: early childhood, primary, and secondary; as well as enabling a comparison between the settings. Teachers' perspectives were sought through questionnaires, reflective jounals, and semi-strucutred interviews.

\subsection{Participants and Context}

The twenty-nine teachers involved in this study were from 10 schools, including two teachers from early learning centres, 18 primary school teachers, and nine secondary school teachers (see Table 1). The participants represented a diverse range of teacher experience, skills, and confidence regarding robotics and digital technology. In addition, the teachers were situated across a variety of demographic and socioeconomic contexts and included teachers from rural, semi-rural, inner metropolitan, from small through to large schools.

The body that represents the independent school sector from one State in Australia purchased the two NAO humanoid robots (see Fig. 1) that were used in this study and then extended an invitation to their 97 principals to submit a brief 
Table 1 Participants

\begin{tabular}{lllll}
\hline Setting & Sites & $\begin{array}{l}\text { Teachers } \\
\text { involved }\end{array}$ & Year levels & Ages of students \\
\hline Early Learning Centre & 2 & 2 & Pre-foundation & 4-5 years \\
Primary School & 8 & 18 & Foundation-Year 6/7 & 5-12 years \\
Secondary School & 4 & 9 & Years 7-10 & 12-15 years \\
\hline
\end{tabular}

Fig. 1 NAO humanoid robots

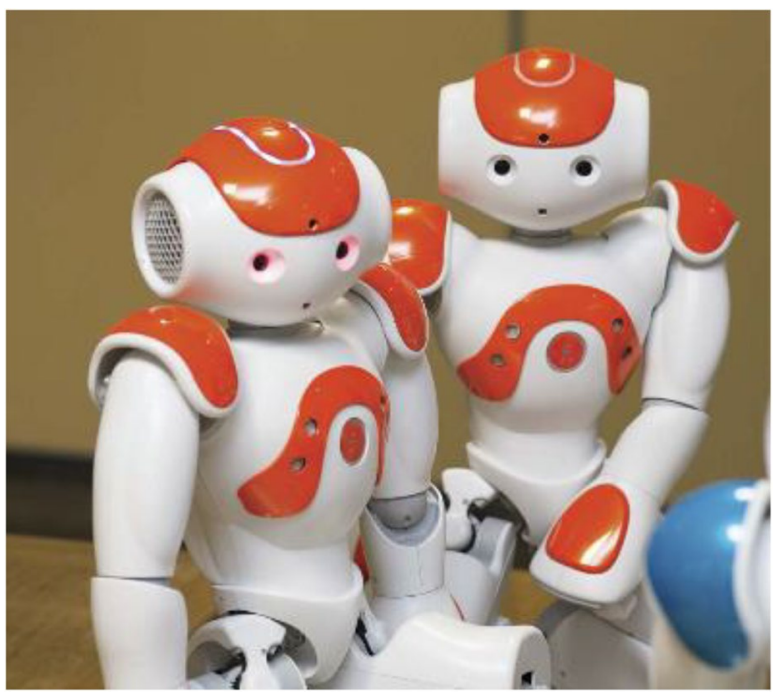

proposal outlining how their school would incorporate the robot into teaching and learning. The principals worked with interested teachers to put together their proposal and the participating schools were selected based on their proposed activity and to ensure that the data collected reflected the diverse demographics of the settings.

The NAO robot is $58 \mathrm{~cm}$ tall, designed in human form with two arms, two legs, a body, and a head. Duirng the study the teachers could opt for different levels of complexity for programming the NAO robot. The different levels of programming included using a drag and drop timeline software (Choregraphe), where programming icons could be 'dragged and dropped' to create 'actions' for the robot to complete, to using a range of text-based programming languages (including Python Programming Language). The robots' movements and sensors, such as sight, sound, touch, and social behaviors, could be programmed. The robot could also be programmed to respond to a range of verbal commands.

Each school had access to one robot for a period of eight weeks to nine months, depending on the proposed activity. Prior to receiving a robot, the teachers were provided with two days of in-service professional development (PD). This PD consisted of programming support and a discussion of effective pedagogical 
approaches and teaching strategies to promote engagement and learning. The teachers were encouraged to develop challenging open-ended authentic learning activities and to collaborate with other teachers.

\subsection{Multiple Case Studies}

This research study used case studies both for richness of data and to be inclusive of all of the schools that participated in the study (Simons, 2009; Stake 1995), and in order to investigate the use of the humanoid robots in the different school settings. Each school setting is explored in-depth to give insights and descriptions integral to understanding the deployment of the humanoid robot. To understand if and how humanoid robots fitted into the curriculum and the value of using humanoid robots in the classroom, the 29 teachers' views over the three years were sought using questionnaires, reflective journals, and semi-structured interviews.

\subsection{Questionnaires}

The questionnaires consisted of 24 open-ended response questions aimed at providing information on three main areas: (1) How the NAO robots were used in the classroom (2) What perceived benefits were achieved and challenges faced when using the robots in the classroom (3) What value the teachers perceived the humanoid robots had in the curriculum. Studies exploring teachers' perceptions regarding the use of robots in the classroom have aked similar questions to investigate the benefits of using robotics-based activites (Bers et al., 2014; Chalmers, 2018). The teachers completed the questionnaires at the end of the robot deployment period with their school. Table 2 aligns the three main focus areas with sample questions from the questionnaire, in order to show how the teachers' views on the use of humanoid robots in the classroom were investigated.

Table 2 Questionnaires

\begin{tabular}{ll}
\hline Focus areas & Sample questions \\
\hline How used in the classroom & - When engaging with NAO, what comments can you make about the \\
& students' learning in terms of innovation and creativity? \\
$\bullet$ & Did the inclusion of NAO in your classroom change how you think \\
about learning and teaching? & - What structural and organisational considerations were required \\
Perceived benefits and challenges & to promote best student learning outcomes with respect to learning \\
& space? \\
- What advice would you give a school principal about humanoid & robots? \\
Curriculum impact & Where in the curriculum do you see the greatest benefits of using \\
& How does using the humanoid robot promote computational think- \\
& ing?
\end{tabular}




\subsection{Reflective Journals}

The teachers were asked to maintain a reflective journal to provide information about how the humanoid robots were used and their perceptions of the benefits and challenges of using the robots. Reflective journals can assist with the reflection on practice and learning "as a way to make sense of what has occurred" (Boud, 2001. p.10). Reflective journals can also provide teachers with the means to successfully adopt new technologies in the classroom (Koszalka, 2003). To assist in their reflection, each week for the period they had the robot in their classroom, participants were asked to respond to five questions regarding the use of a humanoid robot. Table 3 shows how the five questions are related to the three focus areas identified in the research questions for this study: How the robots were used; Perceived benefits and challenges; and Perceived value they have in the curriculum. The participants also commented on and provided examples of the various activities they incorporated when using the humanoid robot in their classroom.

\subsection{Semi-structured Interviews}

Semi-structured interviews were used to clarify and further explore teachers' journal entries and to expand on their responses about their experiences working with the humanoid robot. The interviews were conducted after the robot sessions had been completed, allowing time for participants to reflect and for their views to be clearly articulated (Fontana \& Frey, 2000). Questions were developed to act as an initial guide in framing the interview (Kvale \& Brinkmann, 2009) and to allow for the teachers to discuss their experiences and perceptions on using the humanoid robot with their students. The initial interview questions related to teachers' perceptions of the benefits and challenges of using the NAO humanoid robot in their classroom (see Table 4).

To help identify perceived benefits and challenges, teachers were asked what advice they would give to a school principal about using humanoid robots in the classroom. They were also asked to describe specific structural and organizational considerations relating to the deployment of a humanoid robot, including

Table 3 Reflective journals

\begin{tabular}{ll}
\hline Focus areas & Sample questions \\
\hline How used in the classroom & $\bullet$ How was the robot used in your classroom? \\
& - How did the students in your class engage and interact with the \\
robot? & - How has the robot been beneficial for students' understanding of \\
Perceived benefits and challenges & technology? \\
& - Did you have any concerns or frustrations with the technology? \\
Curriculum impact & why these activities were successful (or not) \\
& - What suggestions do you have for other teachers using humanoid \\
& robots?
\end{tabular}


Table 4 Semi-structured interviews

\begin{tabular}{|c|c|}
\hline Focus areas & Sample questions \\
\hline Engagement & $\begin{array}{l}\text { - How did the children in your class engage and interact with the robot? } \\
\text { - Was student engagement with the NAO robot sustained over time? }\end{array}$ \\
\hline Student learning & - How has the robot impacted on student learning in terms of transferable skills? \\
\hline Curriculum impact & - Where in the curriculum do you see the benefits of using NAO? \\
\hline Pedagogical practices & $\begin{array}{l}\text { - Did any of your pedagogical practices change as a result of having the robot in } \\
\text { the classroom? }\end{array}$ \\
\hline $\begin{array}{l}\text { Structural and organ- } \\
\text { isational factors }\end{array}$ & $\begin{array}{l}\text { - What structural and organisational considerations were required to promote } \\
\text { best student learning outcomes? }\end{array}$ \\
\hline Final thoughts & - What advice would you give another educator about using humanoid robots? \\
\hline
\end{tabular}

recommending the optimal learning space, time allocation, student-teacher ratio and robot-student ratio. To further investigate the use of humanoid robots in the curriculum the teachers were also asked where they saw the greatest benefits of using humanoid robots in the classroom. All interviews were audio-recorded and pertinent comments were transcribed for further analysis.

\section{Analysis}

An analysis of the data collected contributed towards the development of a richer indepth understanding of the whole phenomenon. Audio recordings from the teacher interviews were transcribed and imported to the NVivo Qualitative Analysis software, along with teachers' responses to the questionnaires, and their reflective journals. The collected data was analysed thematically, according to Braun and Clarke (2006), by exploring participants' responses in-depth and coding their responses according to the main themes of how the humanoid robot was used in the classroom, the pedagogical practices that were used, and where the teachers perceived that robots fitted into the curriculum. Thematic analysis involves a thorough examination of the data in order to generate relevant themes (Braun \& Clarke, 2006) and further themes emerged from the responses to the semi-structured interviews. Themes relevant to the study questions were coded first, using a deductive approach, then a constant comparative method was used to discover other common recurring themes (Glaser \& Strauss, 1967). These emergent themes varied by student age, and are incorporated in the results below.

\section{Results}

The findings from this multiple case study indicate that humanoid robots have a positive impact on students' learning and suggest that the humanoid robots may be useful for learning and teaching purposes across a range of school settings (Keane et al., 2020). The teachers reported on the value of using humanoid robots in the classroom, the pedagogical practices that were adopted when the humanoid robot was used, and 
how students engaged with the robot and with their learning. Regarding the use of the humanoid robot, teachers commented on student engagement and on the development of transferable skills including innovation, creativity, collaboration, problem solving, risk-taking, and self-direction. Teachers also discussed changes in their own pedagogical practices with the use of the humanoid robot in their classrooms. Each school setting is explored in-depth to give insights and descriptions integral to understanding the deployment of the humanoid robots in the different settings; to better understand if and how humanoid robots fitted into the curriculum and the value of using humanoid robots in the classroom.

\subsection{Early Learning Centre Settings}

The two early learning centre settings (ELC Setting \#1 \& ELC Setting \#2) involved two educators (EL Teacher \#1 \& EL Teacher \#2), who were teaching pre-school classes for children aged 4-5 (See Table 5). With each class the humanoid robot was used as a tool to generate interest and extension in the areas of computer science and robotics. An inquiry approach was adopted as teachers introduced the robot to the students and the 'discussions were the basis of deep thinking about how the robot worked' (ELC Setting \#1: EL Teacher \#1). The children's understanding became more complex as they drew examples of coding the robot using symbolic representation (numbers, letters, and symbols). This demonstrated an understanding that robots receive messages and they identified that people often send messages through computers' (ELC Setting \#2: EL Teacher \# 2). The children were also involved in 'designing and creating robots in a multitude of ways. For example, construction, clay, experimenting with nuts and bolts, painting, drawing, and collage' (EL Teacher \#2).

Initially, some of the children were hesitant to touch the robot 'but most slowly warmed to him over the course of the day' (EL Teacher \#2). The students became very engaged which was evident as they began to look after the robot 'fetching him a pillow for his rest and reading him stories as well as making gifts of pictures they have drawn' (EL Teacher \#2). The teachers reported that early years students were curious about the robot and maintained their interest with the technology. While the children saw the robot as human-like 'it was obvious that students saw it as a machine. They wanted to know how it works' (EL Teacher \#1). When asked what challenges were faced when using the robot, EL Teacher \#2 stated that it was difficult to get the robot to respond to voice commands, even in a quiet space, because the students were excited to be working with the robot and while it was explained to them that they needed to be quiet 'they still kept mimicking me or each other if I asked them to say the command'.

Table 5 Early learning centre settings

\begin{tabular}{lll}
\hline Year level & Setting number & Teacher number \\
\hline Pre-Foundation level & ELC Setting \#1 & EL Teacher \#1 \\
& ELC Setting \#2 & EL Teacher \#2 \\
\hline
\end{tabular}




\subsection{Primary School Learning Settings}

Eighteen teachers from eight primary schools, for children in Foundation to Year 6/7 classes (ages 5-12), were also involved in this study (see Table 6). The teachers in the primary school (PS) sector mainly used the humanoid robots to introduce robotics, programming, and computational thinking into the classroom. One of the teachers included cutting and pasting activities for students to show their understanding of coding sequences before they went on to the computer and students 'worked with a buddy to design their own coding sequence using string to join the sequence together' (PS Teacher \#4; PS Setting \#1). This teacher also reported that the robot fitted in with the inquiry approach already adopted in the classroom and the students' 'engagement level was very high' as 'students used 'complex software to successfully develop their own coding sequence". The teacher advised other teachers that they should stay open minded as 'I see humanoid robots having an important role in schools' as 'the students in our care have a right to be exposed to this type of technology'.

In Year 2, the humanoid robot was used to introduce programming in the Digital Technologies Learning Area (PS Setting \#2: PS Teacher \#2). Teachers from Year 3 (PS Setting \#1: PS Teacher \#3 \& \#4) used the robot as a 'tool where the class was able to use [the robot] for their own programming' (PS Teacher \#3). Using an 'inquiry model of pedagogy' (PS Teacher \#3) students were encouraged to compare the movement of a human body to the movement of the robot and to look at the differences between robots and humans. One task involved students identifying a need for a robot in their lives. Examples given included: 'to hang out the washing, feed

\begin{tabular}{|c|c|c|c|}
\hline \multirow{19}{*}{$\begin{array}{l}\text { Table } 6 \text { Primary school learning } \\
\text { settings }\end{array}$} & Year level & Setting number & Teacher number \\
\hline & Foundation level & PS Setting \#1 & PS Teacher \#1 \\
\hline & Year 2 & PS Setting \#2 & PS Teacher \#2 \\
\hline & Year 3 & PS Setting \#1 & PS Teacher \#3 \\
\hline & & PS Setting \#1 & PS Teacher \#4 \\
\hline & Year 4 & PS Setting \#3 & PS Teacher \#5 \\
\hline & & PS Setting \#3 & PS Teacher \#6 \\
\hline & Year 5 & PS Setting \#4 & PS Teacher \#7 \\
\hline & & PS Setting \#4 & PS Teacher \#8 \\
\hline & Year 5/6 & PS Setting \#5 & PS Teacher \#9 \\
\hline & & PS Setting \#5 & PS Teacher \#10 \\
\hline & & PS Setting \#5 & PS Teacher \#11 \\
\hline & Year 6 & PS Setting \#6 & PS Teacher \#12 \\
\hline & & PS Setting \#6 & PS Teacher \#13 \\
\hline & & PS Setting \#7 & PS Teacher \#14 \\
\hline & & PS Setting \#7 & PS Teacher \#15 \\
\hline & Foundation -Year 7 & PS Setting \#8 & PS Teacher \#16 \\
\hline & & PS Setting \#7 & PS Teacher \#17 \\
\hline & & PS Setting \#3 & PS Teacher \#18 \\
\hline
\end{tabular}


the birds, help them with their dancing and even feed their baby sister' (PS Teacher \#4). The students were then asked to code the robot to help them with this task. One class of Year 3 students worked with 'buddies' from the Early Learning Centre to 'design their own coding sequence on paper using string to join the sequence together' (PS Teacher \#4). The students 'were all very excited' to have the robot in the classroom and their 'enthusiasm and motivation towards computer science has increased dramatically because of this experience' (PS Teacher \#4). Some students extended their learning as they 'gained momentum and independently researched NAO humanoid robots, especially enjoying the variety of videos available on YouTube' (PS Teacher \#3). There were some technical challenges discussed by PS Teachers \#3 and \#4 including the robot having to be sent away for repairs, however, the robot 'not working didn't seem to hinder the girls' enthusiasm for programming' (PS Teacher \#3). While the robot was away the students were still able to 'trial their sequence on the virtual robot' (PS Teacher \#4).

The Year 4 teachers (PS Setting \#3: PS Teacher \#5 \& PS Setting \#4: PS Teacher \#6) also used an 'inquiry-based and experimental' approach that had their students working with 'buddies' from Year 7 to 'mentor Year $4 s$ to create an animal quiz' (PS Teacher \#5). The Year 7 buddies 'helped them to plan this out on large A2 paper and children were encouraged to include the icons on Choregraphe' (PS Teacher \#6). The teachers reported that the students were highly engaged with this activity and using the robot meant that students were provided with 'real, practical feedback on their programming decisions (e.g. can [the robot] perform the types and combinations of movements in the time they give him)' (PS Teacher \#5). There was 'no obvious gender difference in anticipation or engagement during the sessions' (PS Teacher \#5). All students developed 'decoding and branching skills' (PS Teacher \#6) and 'a number of social skills, including communication, listening, teamwork, problem solving and cooperative skills' (PS Teacher \#6). They 'built their confidence in using and understanding of the technologies involved' (PS Teacher \#5).

Working with the robots developed students' awareness 'of the challenges and successes of the technology, helping their problem-solving skills to develop' (PS Teacher \#6). There were some difficulties with getting the robot to function consistently which affected 'how much we were able to achieve and engagement with the program' (PS Teacher \#5), however, the teachers reported that 'the children all enjoyed the task' (PS Teacher \#6).

There were five teachers working with either Year 5 (PS Setting \#4: PS Teacher \#7 \& PS Teacher \#8) or combined Year 5/6 classes (PS Setting \#5: PS Teacher \#9, \#10, \& \#11). In one school (PS Setting \#4) the robot was incorporated 'into narrative reading \& writing' activities where students had to 'envision a setting in which [the robot] had to get out' (PS Teacher \#7). The school's IT support person would conduct a 'mini-lesson' on Choregraphe, 'then the children could then try their own ideas with the knowledge' (PS Teacher \#7). The students 'gained the confidence and skills to carry out basic coding' (PS Teacher \#8) and using the robot's visual programming tool, Choregraphe. The Year 5 students were able to recognize that 'the robotic behavior is totally dependent on the ability of the programmer' (PS Teacher \#7). Students were also able to 'see the limitations of robotics such as actual physical limitations (i.e. can't go in water, falls over easily etc.)' (PS Teacher \#7). 
The robot was also used for computer classes in PS Setting 5 (PS Teacher \#9, $1 \# 10$ \& \#11). The teachers reported that student engagement was high when students 'problem solved' (PS Teacher \#11) and were 'learning through playing' (PS Teacher \#10). The students were 'very self-directed and enjoyed helping and collaborating with each other' (PS Teacher \#10). The perseverance students developed and their 'determination and grit' 'changed the way students saw themselves as learners' (PS Teacher \#10).

Working on a real-world problem, students in Year 6 were asked to collaboratively program a robot 'to enhance the lives of a particular member of the community' (PS Setting \#6: PS Teacher \#12 \& \#13). The students had to be 'self-directed in order to learn how to use the software to do what they imagined [the robot] could do for their community' (PS Teacher \#12 \& \#13). The students used a range of resources, including online tutorials, to teach them the skills they needed to enable them to program the robot to do what they wanted. There was some frustration with only having one robot to test their program on, however, this problem was solved by 'using teachers' laptop to connect and then all students bought their program on a USB to test' (PS Teacher \#12 \& \#13).

In the Year 6 and 7 classes, students were engaged and 'would interact with [the robot] in a few different ways... to develop and test their Choregraphe projects' (PS Setting \#7: PS Teacher \#14). After the teachers demonstrated what the robot was capable of 'the Year 6 and 7 students were really excited to get onto Choregraphe to see what they could come up with' (PS Setting \#7: PS Teacher \#15). The students spent time 'watching videos, reading blogs and wiki's' and their 'understanding grew, mostly self-directed, of how they could use the code and software, even some Python [programming software] to get it [the robot] to do things' (PS Teacher \#14). The students also reflected on their journey 'in video journals on their iPads as to what they tried to do with [the robot], how it went, challenges faced, and next steps or goals' (PS Teacher \#14). There were some technical issues and the robot was sent away for repairs to the cooling fan. PS Teacher \#14 reported that the 'exoskeleton is really durable, but it seems the inside parts are very sensitive'. PS Teacher \#14 also reported that the voice recognition system 'was touch and go, sometimes working quite well, and other times not at all'.

The humanoid robot was also used across the year levels from Foundation to Year 7 for German language lessons (PS Setting \#7: PS Teacher \#15). The Foundation to Year 3 students used pre-existing games and songs to enhance existing knowledge and to learn the language. The students in Year 4 and 5 focused on learning the names of different sports where they 'needed to use correct pronunciation for [the robot] to understand what was said to them' (PS Setting \#3: PS Teacher \#18]. The Year 6 students used the Choregraphe program to create 'learning experiences to teach the younger students German' (PS Teacher \#15). The teacher in PS Setting \#8 used the robot for Technology lessons, with students from Foundation to Year 7. The students 'embraced' the robot and it was used in 'student-centered learning' (PS Teacher \#16). While the Digital Technologies teacher (PS Teacher \#17) from PS Setting \#3, didn't teach with the robot 'each class I've visited with [the robot] has been highly engaged with much excitement, great enthusiasm, a little trepidation and plenty of good questions!' 


\subsection{Secondary School Learning Settings}

The nine teachers from the secondary settings for Year 7-10 (See Table 7) used the robot with languages, mathematics, and coding activities. Students in Year 7 created a 'program about fractions' (SS Setting \#1: SS Teacher \#1) 'to learn a skill in programming' (SS Teacher \#1) and programmed the robot 'with some of their spelling words and using various gestures' (SS Setting \#2: SS Teacher \#2). While some teachers emphasized that 'the robot can be integrated into any curriculum area' (SS Teacher \#8) many saw the greatest benefits of using the robot was in 'the areas of Digital Technology and STEM' (SS Setting \#3: SS Teacher \#9) and 'information technology, science and digital studies. By using a robot in these subjects students can develop greater knowledge and understanding in a more meaningful way' (SS Setting \#3: SS Teacher \#3). Incorporating the robot within a technology subject ensured 'a range of learning took place in the types and use of sensors and control systems' (SS Setting \#4: SS Teacher 7). Using the robot 'gave students the opportunities to be creative and question the technology rather than just be passive users' (SS Teacher \#3).

The robot was also used with mathematics in Year 8. The teacher from SS Setting \#2 (SS Teacher \#4) used the robot to 'look at computational thinking and how programming [a robot] can enhance the understanding of algorithms' (SS Teacher \#4). The students worked together in teams to create an algorithm for making a sandwich, which was demonstrated to their teacher. Students in SS Setting \#3 also 'devised an end-product [for the robot] that related to mathematics and to our inquiry' (SS Teacher \#3).

The teachers reported that most students in Years 9 and 10 'appeared to enjoy the experience' (SS Setting \#4: SS Teacher \#6) of working on activities where they had the robot 'performing with various actions including movement and sound' (SS Setting \#5: SS Teacher \#8). The activities that the teachers planned were 'design brief based' that enabled students 'to design a solution, test the solution and evaluate the result' (SS Teacher \#6). Students 'took charge of their learning process' and developed 'collaborative skills through deep learning tasks in which they worked on complex problems' (SS Teacher \#9). The students were able to 'display their creativity

Table 7 Secondary school learning settings

\begin{tabular}{lll}
\hline Year level & Setting number & Teacher number \\
\hline Year 7 & SS Setting \#1 & SS Teacher \#1 \\
& SS Setting \#2 & SS Teacher \#2 \\
Year 7/8 & SS Setting \#3 & SS Teacher \#3 \\
Year 8 & SS Setting \#2 & SS Teacher \#4 \\
+ Coding Club (7 - 10) & SS Setting \#2 & SS Teacher \#5 \\
Year 9 & SS Setting \#4 & SS Teacher \#6 \\
& SS Setting \#4 & SS Teacher \#7 \\
Year 9 \& 10 & SS Setting \#5 & SS Teacher \#8 \\
Year 9-10 & SS Setting \#3 & SS Teacher \#9 \\
\hline
\end{tabular}


using various elements of the technology' (SS Teacher \#6). Initially the 'majority of students were very keen to interact with the robot' due to its novelty factor, however, once they became familiar with the robot and the Choregraphe software their perceptions 'changed to seeing the robot as more of a controllable machine' (SS Teacher \#7). The teacher from SS \#4 acknowledged, 'the experiences students were given just touched the very basics of what the robot can achieve' (SS Teacher \#7).

\subsection{Value of Humanoid Robots in the Classroom}

The teachers in each school setting discussed the value of using the technology in the classroom. In the Early Learning settings, young students created basic algorithms with paper and string outlining their thought and sequencing patterns and then with the assistance of their teacher used these instructions to code the robot. The students were able to receive instant feedback on their instructions based on how the robot behaved. The teachers reported that students were captivated by the robot and quickly realized that they were able to manipulate and control the robot based on their instructions. One teacher stated that the challenge presented 'would vary for each individual. But there has certainly been a depth of learning that has been evident' (EL Teacher \#1).

In the primary school settings, students developed computational thinking skills of decoding and branching and a number of social skills, including communication, listening, teamwork, problem solving, and cooperative skills. The students were able to use the robot in many subjects such as German language classes, English, and Digital Technologies. The robot was also used as a discussion starter and integrated into narrative reading and writing activities. One teacher commented that 'the openended opportunity presented by NAO' had also helped develp students' $21^{\text {st }}$ century skills of 'creativity and innovation, critical thinking and problem solving, communication, digital literacy, collaboration, and leadership are all presented by students' (PS Teacher \#16).

In the secondary school settings, the robots were integrated into many different subject disciplines such as German language classes, Mathematics, Digital Technologies and integrated STEM classes. The humanoid robots were used in a variety of ways including learning about sensors and control systems, programming and developing algorithms. The students adapted their algorithms to include repeats/loops and more precise language as they became more confident in their abilities. The teachers commented that students' learning was due to the relevance and engagement with the robots and one teacher stated that the 'robot application provided a hit with some of the more relunctlant students' (SS Teacher \#4). Teachers from all three education settings reported that students found working with the robots to be fun and relevant.

\subsection{Effective Pedagogical Practices}

A constructivist inquiry approach was adopted by most teachers as they introduced the robot and held discussions with students about how the robot worked. While this approach fitted in with the inquiry approach already adopted at many schools in this 
study, one teacher stated that the inclusion of the robot in the classroom made them rethink their pedagogy to allow for 'high levels of engagement with different points of entry' (PS Teacher \#1). The importance of reviewing pedagogy is emphasized by Fullan and Langworthy (2013), who argued that only through pedagogical innovation will technology be able to "achieve its potential to impact learning" (p.21).

A collaborative approach to teaching was identified as being the most effective when introducing the robot programming; whereby the classroom was student-centered, the learning was shared, and knowledge was built by working with students to trial various techniques and ideas. One teacher stated that students took charge of their learning process and developed 'collaborative skills through deep learning tasks in which they worked on complex problems' (SS Teacher \#4). Teachers also benefited from the 'collaboration between educators was also extremely beneficial throughout the project work' (EL Teacher \#2). This teacher also spoke about the importance of teachers using the reflection journal to 'document every phase. This helped to take the project to a deeper level'.

The teachers adjusted the complexity of the activities to enable students to build confidence in working with the robot. This afforded students the ability to extend their learning and challenged students at their level. The teachers described the various ways students were challenged by the programming activities and how the robots provided an opportunity for differentiated, self-directed learning to take place. One teacher commented that using the robot provided students with the scope to 'display their creativity using various elements of the technology' (SS Teacher \#7). The perseverance students developed and portrayed during the study also changed the way some teachers saw their students as learners and one teacher commented 'having the NAO [humanoid robot] will show you more about a student's way of thinking, abilities and strengths than any test will ever reveal' (PS Teacher \#4).

\subsection{Engagement}

Teachers reported that by having a physical robot that provided immediate feedback on students' coding increased engagement across a wide range of learners. Being "irresistibility engaging" is described by Fullan $(2015$, p.6) as the first of the five elements essential for learning with technology. Students were highly engaged and maintained their enthusiasm throughout their interaction and programming with the robot. Problem solving skills were developed while students were engaged in basic and sophisticated programming. Teacher PS\#4 commented that 'the persistence that I saw students demonstrate during our coding lesson was incredible'. Students enthusiastically collaborated with their peers and shared their knowledge of the software and by programming the robot, the students were making their thinking visible.

The teachers commented that while students were curious and motivated to engage with the humanoid robot, they had underestimated the depth of the relationship the students would develop with the robot. Teachers expressed surprise at the affection demonstrated for the robot by students and stated that many students saw the robot as a human; a small friend or a younger sibling. More than one teacher commented that students had developed feelings for the robot and that most students 
had treated the robot'as an accepted member of the class' (PS Teacher \#1). With younger students (4-5-years old), EL Teacher \#2 reported that some students were initially hesitant to touch the robot but slowly built up their confidence 'over the course of the day' when they saw other children interacting with the robot. As students became familiar with the robot, they all started treating the robot as something they could control. This change in perception was evident even with students in the early years of school as 'it was obvious that students saw it as a machine. They want to know how it works' (EL Teacher \#2).

\subsection{Benefits}

Using the robot in the classroom not only developed students' computational thinking skills, students were also able to develop communication, collaboration, and critical and creative thinking. These skills have been identified as important in the 21st century and underpin the skillset needed in many other disciplines (Eguchi, 2013; Keane et al., 2016b). Alongside these transferable skills, students also developed 'persistence and resilience' (SS Teacher \#8) as they experienced frustration with the programming of the robot. There were times that the robot did not work how they hoped it would, or the outcome was not what was expected. One teacher commented that the persistence that students demonstrated during their coding lessons was incredible. 'I believe that this was the greatest benefit for the students in my class' (PS Teacher \#4). Students began to understand the technology; what it entailed, and how they could control it. The students also understood that robotic behavior is dependent on the ability of the programmer. Students were able to determine the limitations of the robot, such as actual physical limitations including 'can't go in water, falls over easily' (PS Teacher \#7). Through persistence and perseverance, students also developed confidence in interacting with new technologies as they engaged willingly to generate solutions to problems using the NAO robot.

\subsection{Challenges}

Students were mainly positive when working with the NAO robot, but there were also issues that challenged both students and teachers. Issues included the voice recognition component of the robot not working consistently. Teachers commented that the voice recognition/hearing sensors were inconsistent and temperamental and at times the robot 'had trouble understanding the students' (SS Teacher \#4). While the voice recognition issues caused frustration with some students, other students identified the problem was with the ability of the robot and not their programming. Other issues included some aspects of the robot's moveable hardware becoming inoperable after intensive use. Motors (controlling the robot's movement) overheated easily and this caused the robot to stop working. Students found it frustrating when the robot became inoperable and could not continue working with it and some issues resulted in the robot being sent overseas to be repaired. As one teacher recollected 'the cooling fan in her head failed, and the motors in her arm and leg on one side was damaged so had to go to Paris to get fixed' (PS Teacher \#15). A virtual robot was used 
while the robot was being repaired, however, this has limited functionality compared to the physical robot. Some schools also experienced issues with Wi-Fi connections dropping out between the robot and the school network which meant that the robot was not always able to receive code. One teacher noted, this was 'quite frustrating at times', however, the robot not working 'didn't seem to hinder their enthusiasm for programming' (PS Teacher \#3).

\section{Discussion}

This study examined the value of using humanoid robots in the classroom, the specific pedagogical practices that were adopted, and the teachers' perceptions of the benefits and challenges of using the robots in their classrooms. Teacher questionnaires provided insights into the use of the humanoid robots, student engagement, and changes in pedagogical practices. To assist in this reflection, teachers also maintained a journal each week and provided examples of their relevant activities. Semi- structured interviews helped clarify and further explore teachers' journal responses. The results show that the teachers adopted a social constructivist learning approach when introducing the robot in their classrooms. This approach emphasizes students co-constructing their knowledge and understanding through social interaction (Vygotsky, 1978). While this approach was already in use in many of the classrooms, some teachers stated that they needed to rethink their pedagogy to allow for a more collaborative classroom where both teachers and students were able to share their knowledge and collaboratively problem solve.

The findings show that the teachers used the robot as a tool to enhance the curriculum and valued the use of the robot to engage students with various activities (Keane et al., 2020). The teachers reported that they had underestimated the depth of relationship the students would develop with the humanoid robot and that student engagement was maintained even as the students quickly realized they were able to manipulate and control the robot. This finding is consistent with findings by Kanda et al. (2008), Ioannaou et al. (2015), and Pereira et al. (2011) who found that young children established 'friendly relationships' with humanoid robots who expressed encouraging comments.

A number of other benefits were also identified in this study, including students' development of 21 st Century Skills; computational thinking, communication, collaboration, and critical and creative thinking. These skills are core skills for students to be successful in the 21st century (Eguchi, 2013). Researchers have also highlighted the importance of students developing perseverance as programming and operating a physical robot adds complexities that can often be disregarded (Belpaeme et al., 2018). The teachers in this study reported that their students had developed persistence and perseverance as they engaged in creating solutions involving the physical limitations of the humanoid robots (i.e. fall over easily). Other challenging issues relevant to the operation of the robot included inconsistent sensors and over-heating of the robot motors. While these issues caused frustration with some students, the teachers reported that students were motivated to continue their activity using the virtual robot, while the humanoid robot was being repaired. 
Limitations While 29 teachers from 10 schools participated in this study the findings cannot be generalized to all contexts as the results are based on one independent school sector. This study is also limited in duration as schools, depending on the proposed activity, had various times with the robot and some schools also shared the robot amongst a number of classes. Moreover, humanoid robots have their own technical limitations and only one type of humanoid robot (NAO) was used in this study.

\section{Conclusion}

While research with humanoid robots is relatively new, the NAO robot is currently used in many school contexts including early childhood settings (Crompton et al., 2018). This study adds to the existing research by reporting on teachers' views on how these robots fitted into the curriculum, the pedagogical practices used, and their perceived value of using the humanoid robots in their classrooms (Keane et al., 2019). Teachers discovered that there were numerous ways that the robot could be used to enhance the curriculum, from introducing robotics, coding and computational thinking to using the robot to engage students with German Language and Mathematics classes. Most teachers adopted a social constructivist approach to teaching with the humanoid robot and reported that students were highly engaged with their learning when programming and working with the robot. Although teachers noted that some students became frustrated when the robot had to be sent away for repairs or if it didn't do what they expected, the students were motivated to continue the activities and displayed perseverance when programming the robot. The findings from this study support the deployment of humanoid robots across the curriculum and advocate a constructivist inquiry approach to teaching with humanoid robots. Further studies with different humanoid robots, a more consistent approach to the type of activity used, and the duration of the use of the robot, would help inform if student engagement with humanoid robots can be sustained over time.

Funding Open Access funding enabled and organized by CAUL and its Member Institutions.

Data availability Due to the nature of this research, participants of this study did not agree for their data to be shared publicly, so supporting data is not available.

\section{Declarations}

Conflicts of interests/Competing interests The authors have no relevant financial or non-financial interests to disclose, and no conflicts of interest or competing interests relevant to the content of this article.

Open Access This article is licensed under a Creative Commons Attribution 4.0 International License, which permits use, sharing, adaptation, distribution and reproduction in any medium or format, as long as you give appropriate credit to the original author(s) and the source, provide a link to the Creative Commons licence, and indicate if changes were made. The images or other third party material in this article are included in the article's Creative Commons licence, unless indicated otherwise in a credit line to the material. If material is not included in the article's Creative Commons licence and your intended use is not permitted by statutory regulation or exceeds the permitted use, you will need to obtain permission directly from the copyright holder. To view a copy of this licence, visit http://creativecommons.org/licenses/by/4.0/. 


\section{References}

Alimisis, D. (2012). Integrating robotics in science and technology teacher training curriculum. Paper presented at the 3rd International Workshop Teaching Robotics, Teaching with Robotics Integrating Robotics in School Curriculum, Riva del Garda (Trento, Italy). https://www.terecop.eu/TRTWR 2012/trtwr2012_submission_28.pdf

Alimisis, D. (2013). Educational robotics: Open questions and new challenges. Themes in Science and Technology Education, 6(1), 63-71 http://earthlab.uoi.gr/theste/index.php/theste/article/view/119

Barak, M., \& Zadek, Y. (2009). Robotics projects and learning concepts in science, technology, and problem solving. International Journal of Technology \& Design Education, 19(3), 289-307. https://doi. org/10.1007/s 10798-007-9043-3

Barker, B. S., \& Ansorge, J. (2007). Robotics as means to increase achievement scores in an informal learning environment. Journal of Research on Technology in Education, 39(3), 229-243. https://doi. org/10.1080/15391523.2007.10782481

Belpaeme, T., Kennedy, J., Ramachandran, A., Scassellati, B., \& Fumihide, T. (2018). Social robots for education: A review. Science Robotics, 3(21), 1-9. https://doi.org/10.1126/scirobotics.aat5954

Benitti, F. B. V. (2012). Exploring the educational potential of robotics in schools: A systematic review. Computers \& Education, 58(3), 978-988. https://doi.org/10.1016/j.compedu.2011.10.006

Bers, M. U. (2008). Blocks, robots and computers: Learning about technology in early childhood. Teacher's College Press.

Bers, M. U., Flannery, L., Kazakoff, E. R., \& Sullivan, A. (2014). Computational thinking and tinkering: Exploration of an early childhood robotics curriculum. Computers \& Education, 72, 145-157. https://doi.org/10.1016/j.compedu.2013.10.020

Bers, M. U., \& Portsmore, M. (2005). Teaching partnerships: Early childhood and engineering students teaching math and science through robotics. Journal of Science Education and Technology, 14(1), 59-73. https://doi.org/10.1007/s10956-005-2734-1

Boud, D. (2001). Using journal writing to enhance reflective practice. In L. M. English, L. M. and M. A. Gillen (Eds.), Promoting Journal Writing in Adult Education. New Directions in Adult and Continuing Education No. 90., pp 9-18. San Francisco: Jossey-Bass, https://asset-pdf.scinapse.io/prod/ 2164203517/2164203517.pdf

Braun, V., \& Clarke, V. (2006). Using thematic analysis in psychology. Qualitative Research in Psychology, 3(2), 77-101. https://doi.org/10.1191/1478088706qp063oa

Ceha, J., Law, E., Kulić, D., Oudeyer, P., \& Roy, D. (2021). Identifying functions and behaviours of social robots for in-class learning activities: Teachers' perspective. International Journal of Social Robotics. https://doi.org/10.1007/2Fs12369-021-00820-7

Cejka, E., Rogers, C., \& Portsmore, M. (2006). Kindergarten robotics: Using robotics to motivate math, science, and engineering literacy in elementary school. International Journal of Engineering Education, 22(4), 711-722 https://www.ijee.ie/articles/Vol22-4/03_ijee1804.pdf

Castledine, A., \& Chalmers, C. (2011). LEGO robotics: An authentic problem-solving tool? Design and Technology Education: An International Journal, 16(3), 19-27 https://ojs.lboro.ac.uk/DATE/article/ download/1661/1562

Chambers, J., \& Carbonaro, M. (2003). Designing, developing and implementing a course on Lego robotics for technology teacher education. Journal of Technology and Teacher Education, 11(2), 209-241 https://www.learntechlib.org/p/14607/

Chalmers, C. (2018). Robotics and computational thinking in primary school. International Journal of Child-Computer Interaction., 17, 93-100. https://doi.org/10.1016/j.ijcci.2018.06.005

Creswell, J. W. (2008). Educational research: Planning, conducting and evaluating quantitative and qualitative research (3rd ed.). Pearson/Merrill Prentice Hall.

Crompton, H., Gregory, K., \& Burke, D. (2018). Humanoid robots supporting children's learning in an early childhood setting. British Journal of Educational Technology [Special Issue], 49(5), 911-927. https://doi.org/10.1111/bjet.12654

Eguchi, A. (2013). Educational robotics for promoting 21st century skills. Journal of Automation Mobile Robotics and Intelligent Systems, 8(1), 5-11. https://doi.org/10.14313/JAMRIS_1-2014/1

Eickelmann, B., \& Vennemann, M. O. (2017). Teachers' attitudes and beliefs regarding ICT in teaching and learning in European countries. European Educational Research Journal., 16(6), 733-761. https://doi.org/10.1177/1474904117725899 
Fontana, A., \& Frey, J. H. (2000). The interview: From structured questions to negotiated text. In N. K. Denzin \& Y. S. Lincoln (Eds.), Handbook of qualitative research (2nd ed., pp. 645-672). Sage.

Fridin, M., \& Belokopytov, M. (2014). Embodied robot versus virtual agent: Involvement of preschool children in motor task performance. International Journal of Human-Computer Interaction, 30(6), 459-469. 10.1080/10447318.2014.888500

Fullan, M. (2015). Leadership in a digital age. ACEL monograph series -The William Walker oration (Vol. 52). Sydney, Australia: ACEL

Fullan, M., \& Langworthy, M. (2013). New pedagogies for deeper learning. Washington: Collaborative Impact.

Glaser, B., \& Strauss, A. (1967). The discovery of grounded theory: Strategies for qualitative research. Sociology Press.

Ioannaou, A., Andreou, E., \& Christofi, M. (2015). Pre-schoolers' interest and caring behaviour around a humanoid robot. TechTrends, 59(2), 23-26. https://doi.org/10.1007/s11528-015-0835-0

Jonassen, D. H. (2000). Computers as mindtools for schools: Engaging critical thinking. New Jersey: Prentice Hall.

Kanda, T., Nishio, S., Ishiguro, H., \& Hagita, N. (2008). Interactive humanoid robots and androids in children's lives. Children, Youth and Environments, 19(1), 12-33. https://www.jstor.org/stable/10. 7721/chilyoutenvi.19.1.0012

Keane, T., Boden, M., Chalmers, C., \& Williams, M. (2020). Effective principal leadership influencing technology innovation in the classroom. Education and Information Technologies, 25, 5321-5338. https://doi.org/10.1007/s10639-020-10217-0

Keane, T., Chalmers, C., Boden, M., \& Williams, M. (2019). Humanoid robots: learning a programming language to learn a traditional language. Technology, Pedagogy and Education, 28(5), 533-546. https://doi.org/10.1080/1475939X.2019.1670248

Keane, T., Chalmers, C., Williams, M., Boden, M. (2016a). The impact of humanoid robots on students' computational thinking. Australian Conference on Computers in Education (ACCE 2016), Brisbane, Australia, 29 September-2 October.

Keane, T., Keane, W. F., \& Blicblau, A. S. (2016b). Beyond traditional literacy: Learning and transformative practices using ICT. Education and Information Technologies, 21(4), 769-781. https://doi.org/ 10.1007/s10639-014-9353-5

Koszalka, T. A. (2003). Reflection as a critical component of the technology adoption process. ERIC Document Reproduction Services ED, 480, 237. https://www.ericdigests.org/2005-2/reflection.html

Kvale, S., \& Brinkmann, S. (2009). Interviews: Learning the craft of qualitative research interviewing. Sage.

Papert, S. (1993). Mindstorms: Children, computers, and powerful ideas (2nd ed.). The Perseus Books Group.

Pedaste, M., \& Altin, H. (2020). Does inquiry-based education using robots have an effect on learners' inquiry skills, subject knowledge and skills, and motivation? International Journal on Advanced Science Engineering and Information Technology, 10(4), 1403-1409. https://doi.org/10.18517/ijase it.10.4.12766

Pereira, A., Leite, I., Mascarenhas, S., Martinho, C., \& Paiva, A. (2011). Using empathy to improve human-robot relationships. In M. H. Lamers \& F. J. Verbeek (Eds.), Human-Robot Personal Relationships (pp. 130-138). Springer.

Simons, H. (2009). Case study research in practice. SAGE publications.

Stake, R. E. (1995). The art of case study research. Sage.

Stake, R. E. (2006). Multiple case study analysis. Guilford Press.

Vygotsky, L. (1978). Mind in society: The development of higher psychological processes, eds. M. Cole, V. John-Steiner, S. Scribner, \& E. Souberman. Cambridge: Harvard University Press.

Welch, A., \& Huffman, D. (2011). The effect of robotics competitions on high school students' attitudes toward science. School Science and Mathematics, 111(8), 416-424. https://doi.org/10.1111/j.19498594.2011.00107

Yadav, A., Stephenson, C., \& Hong, H. (2017). Computational thinking for teacher education. Communications of the ACM, 60(4), 55-62.https://edtechbooks.org/-TNhttps://doi.org/10.1145/2994591

Publisher's note Springer Nature remains neutral with regard to jurisdictional claims in published maps and institutional affiliations. 